\title{
Pengaruh kualitas pelayanan, citra merek dan kepuasan pelanggan terhadap loyalitas pelanggan pada kafe di kota Batam.
}

\author{
Hanny \\ Universitas Internasional Batam \\ hanny@uib.ac.id \\ Krisyana \\ Universitas Internasional Batam
}

\begin{abstract}
Abstrak Pada era globalisasi sekarang, industri jasa seperti usaha makanan dan minuman sedang berkembang pesat di Indonesia. Dari segi penataan makanan dan minuman yang unik, bagus dan kreatif membuat masyarakat ingin mengonsumsinya. Salah satu makanan yang disukai oleh masyarakat adalah makanan penutup. Dengan semua data survei yang diisi oleh peserta survei, maka peneliti dapat meneliti dan mengetahui apakah terdapat pengaruh kualitas pelayanan, citra merek, dan kepuasan pelanggan terhadap loyalitas pelanggan pada kafe di Kota Batam. Data yang telah terkumpul dilakukan dengan menyebarkan kuesioner melalui internet dan di analisa oleh peneliti untuk membuktikan bahwa variabel-variabel yang bersifat independen seperti kualitas pelayanan, citra merek dan kepuasan pelanggan dapat berpengaruh pada variabel dependen yaitu loyalitas pelanggan.

Setiap variabel ini telah diteliti sebelumnya sehingga peneliti dapat memilih keempat variabel ini sebagai bahan penelitian. Populasi pada penelitian ini adalah penduduk yang tinggal di Kota Batam, penduduk yang pernah mengunjungi kafe di Kota Batam, dan penduduk yang pernah memesan makanan penutup di kafe Kota Batam. Isi penelitian ini dapat berguna bagi berbagai pihak organisasi pariwisata.

Tujuan dilakukan penelitian pada variabel kualitas pelayanan, citra merek, kepuasan pelanggan dan loyalitas pelanggan untuk menambahkan karya ilmiah dan untuk referensi bagi pembaca. Hasil dari penelitian pada variabel independen terdapat pengaruh positif terhadap variabel dependen.
\end{abstract}

\section{Kata Kunci Kualitas Pelayanan, Citra Merek, Kepuasan Pelanggan, Loyalitas Pelanggan}

\section{PENDAHULUAN}

Sebuah industri jasa seperti usaha makanan dan minuman sedang berkembang di Indonesia. Makanan merupakan bahan yang berasal dari hewan dan tumbuhan yang dikonsumsi oleh makhluk hidup untuk memperoleh energi dan nutrizi. Kebutuhan manusia diperoleh dari hasil bertani atau berkebun, contohnya dari sumber hewan dan tumbuhan. Minuman merupakan cairan yang ditelan atau diminum. Minuman dapat 
dihidangkan dalam bentuk minuman hangat, panas dan dingin. Selain itu, minuman juga terdapat beberapa rasa (manis, asam, dan pahit).

Semakin berkembangnya era globalisasi, makanan dan minuman pada jaman sekarang ini terdapat banyak variasi yang baru. Pada jaman dahulu, makanan hanya terdapat nasi, sayur, buah-buahan dan daging. Sedangkan, jaman sekarang makanan terdapat steak, spaghetti, roti, dan kue-kue (snack). Minuman juga semakin berkembang menjadi latte, smoothie, thai tea dan milkshake. Padahal jaman dahulu hanya memiliki air putih, kopi, susu dan wedang jahe. Selain itu, juga terdapat jajanan yang berada di tepi jalan atau biasanya terdapat gerobak kaki lima.

Perubahan di atas terjadi dikarenakan semakin berkembangnya jaman, apalagi masyarakat sekarang sudah memiliki smartphone dengan jaringan internet dan mempunyai media sosial. Orang-orang akan mengikuti tren yang ada diluar negeri. Sehingga bermunculan makanan dan minuman yang berinovasi dan rasa baru, serta memiliki penampilan yang sangat menarik perhatian masyarakat. Dari segi tata makanan dan minuman yang unik, bagus dan kreatif membuat masyarakat.

ingin mengonsumsinya. Jadi, makanan dan minuman masih menjadi topik yang menarik untuk di teliti.

Beberapa perusahaan yang beroperasi di bidang makanan dan minuman yang menarik perhatian peminat, terutama makanan penutup (dessert) yang ada di Batam, seperti Biscotti Cakery \& Coffee, Meilleur Café \& Patisserie, Caffein Coffee \& Cake, Lee's Café \& Bar, Tatido Coffee Roasters, Pinkupansa Cakery, Piccola Stella, Chemistree, Anchor Café \& Roastery dan Simetri Coffee. Alasan memilih 10 tempat tersebut karena kafe tersebut menjual berbagai macam kue yang memiliki khas diri sendiri.

Berdasarkan data statistik dari Kementrian Pertanian pada tahun 2017, produk roti mengalami kenaikan persentasi hampir 50\% selama lima tahun ke belakang. Produk yang dikonsumsi adalah produk roti, seperti roti putih. Selain roti putih, produk roti lainnya seperti kue kering, roti-roti, dan kue juga mengalami kenaikan persentase. Badan Pusat Statistik (BPS) merilis data pertumbuhan industri informasi dan komunikasi yang positif di Kota Batam.

\section{LANDASAN TEORI}

\section{A. Loyalitas Pelanggan (Customer Loyalty)}

Loyalitas pelanggan adalah perilaku nyata klien terhadap beberapa hal yang terkait dengan perusahaan seperti: kategori barang atau jasa, nama merek, dan citra merek (Anh et al., 2020). (Chiou et al., 2020) mendefinisikan loyalitas pelanggan sebagai perilaku di mana perhatian diberikan kepada penyedia layanan atau perilaku yang terjadi sebagai reaksi terhadap perilaku positif penyedia layanan.

Dalam industri pariwisata, (Chiou et al., 2020) mendefinisikan loyalitas sebagai niat turis untuk mengunjungi kembali dan rekomendasinya kepada orang lain. (Durmaz et al., 2018) mendefinisikan loyalitas pelanggan sebagai kondisi perilaku. (Y Ferdiawan et al., 2018), mengungkapkan loyalitas pelanggan adalah suatu keterikatan pelanggan pada suatu merek, toko, atau distributor, yang memiliki sikap sangat positif terhadap pengulangan pembelian yang konsisten. (Hafez \& Akther, 2017) menyatakan loyalitas pelanggan sebagai "Komitmen erat pada pilihan produk atau jasa secara konsisten di masa depan, sehingga terjadi pembelian merek yang sama berulang kali. Loyalitas pelanggan adalah pelanggan loyal yang senantiasa membeli ulang, yang menjamin aliran pendapatan bagi perusahaan, ia memiliki keinginan membeli lebih banyak, ingin membayar dengan 
harga lebih tinggi atau mahal, yang akan berpengaruh langsung pada laba perusahaan (Tantri Yanuar R. Syah, 2019). Loyalitas pelanggan merupakan keinginan pelanggan untuk terus berbisnis dengan perusahaan dari waktu ke waktu (Irshad et al., 2017). (Jung et al., 2020) mendefinisikan kesetiaan sebagai "Keinginan kuat untuk berbelanja atau mengunjungi produk atau layanan yang konsisten dan disukai, bahkan jika konsumen berada dalam situasi yang dapat memicu tindakan konversi untuk memilih merek lain. Loyalitas pelanggan adalah strategi yang menciptakan saling menguntungkan untuk perusahaan dan pelanggan yang menguntungkan (Ying Lee, 2019). Loyalitas pelanggan adalah sumber keunggulan kompetitif yang berkelanjutan (Makanyeza \& Chikazhe, 2017). Loyalitas pelanggan adalah tingkah laku yang mendorong perilaku untuk membeli produk atau jasa dari suatu perusahaan yang mencakup aspek perasaan di dalamnya, terutama mereka yang berulang kali membeli secara teratur dengan konsistensi tinggi, selain membeli ulang barang dan jasa, juga memiliki komitmen dan sikap positif terhadap perusahaan yang menawarkan produk atau layanan (Minar \& Safitri, 2017). Definisi (C. Njelita \& Marcus, 2020) menyatakan bahwa loyalitas pelanggan adalah respon perilaku yang bisa diekspresikan oleh beberapa individu sehubungan dengan satu atau lebih alternatif dari sekumpulan alternatif. Menurut (Sukerta et al., 2020) loyalitas adalah respon perilaku yang dinyatakan dalam periode tertentu oleh unit pengambilan keputusan dalam kaitannya dengan satu pembuat keputusan atau lebih alternatif merek yang dipilih dari serangkaian merek, dan fungsi dari proses psikologis. Loyalitas pelanggan itu sendiri dapat didefinisikan sebagai kesediaan pelanggan untuk mengunjungi dan membeli kembali produk atau layanan dari industri yang sama (Wilson, 2018). Loyalitas pelanggan didefinisikan sebagai pembelian berulang atas produk atau layanan tertentu oleh pelanggan (Khokhar \& Khokhar, 2020).

\section{Kualitas Pelayanan}

Kualitas adalah kombinasi dari spesifik produk dan layanan dari hasil pemasaran, rekayasa, produksi dan menjaga pembuatan produk dan layanan yang digunakan untuk mencukupi keinginan pelanggan (WIJAYA, 2011). Kualitas pelayanan ialah suatu kondisi dinamis yang berkaitan dengan produk, layanan, manusia, alam, dan lingkungan yang memenuhi keinginan (Tjiptono, 2006). Beberapa peneliti mengungkapkan pentingnya kualitas layanan dalam lingkungan bisnis, dimana kualitas layanan menjadi variabel penting yang dapat menjamin keberhasilan dan kelangsungan hidup perusahaan dalam industri(Fotaki, 2015); (Ismail \& Yunan, 2016); (Ali et al., 2016).

Kualitas pelayanan dapat didefinisikan sebagai upaya pelanggan untuk membandingkan kualitas layanan yang diharapkan oleh konsumen (diharapkan) dengan layanan aktual yang dilakukan oleh perusahaan(Czepiel, 1990); (Cronin \& Taylor, 1992); (Agyapong, 2011); (Fauzi, 2018). Maka dapat disimpulkan, bahwa kualitas layanan ialah memenuhi sesuatu yang diinginkan atau diperlukan bagi konsumen dan bagaimana tingkat pelayanan yang diberikan untuk memenuhi harapan konsumen.

\section{Citra Merek}

Citra merek dapat diartikan sebagai kesan pelanggan mengenai merek yang disimpan dalam ingatan pelanggan(Saleem \& Raja, 2014); (Lahap et al., 2016). Citra merek merupakan sebuah kesan keseluruhan konsumen tentang suatu merek, di mana kesan tersebut dibentuk oleh kombinasi pengenalan, perasaan dan sikap terhadap merek tersebut, (Tucker \& Levy, 1979). Dalam branding, citra merek berperan sangat penting dalam membentuk persepsi konsumen terhadap suatu merek. Citra merek adalah hal 
pertama yang terlintas di benak pelanggan saat membeli produk (Meyer \& Meyer, 2016); (Durmaz et al., 2018). Terdapat banyak penelitian yang membuktikan bahwa terdapat interaksi positif antara loyalitas pelanggan dan citra merek(Kusumah, 2018); (Y Ferdiawan et al., 2018); (Azizan \& Yusr, 2019)).

\section{Kepuasan Pelanggan}

Kepuasan adalah respon atau tanggapan konsumen untuk memenuhi kebutuhan. Kepuasan pelanggan bertindak sebagai faktor dasar loyalitas pelanggan yang meningkatkan pengulangan pembelian dan membantu penyebaran mulut ke mulut yang lebih positif (Reichheld \& Sasser, 1990). Sedangkan menurut (Dölarslan, 2014) kepuasan pelanggan berdampak langsung terhadap loyalitas. Kepuasan pelanggan sangat penting untuk niat membeli kembali.

Kepuasan pelanggan bertindak sebagai mediator antara dimensi kualitas layanan yang dirasakan dan loyalitas pelanggan. Definisi yang dijelaskan oleh para peneliti, dapat disimpulkan bahwa kepuasan ialah anggapan seseorang yang timbul dari hasil pembelian setelah membandingkan kinerja produk yang mereka anggap diharapkan oleh pelanggan. Menurut beberapa studi (Hafez \& Akther, 2017); (Anh et al., 2020); (Khokhar \& Khokhar, 2020)

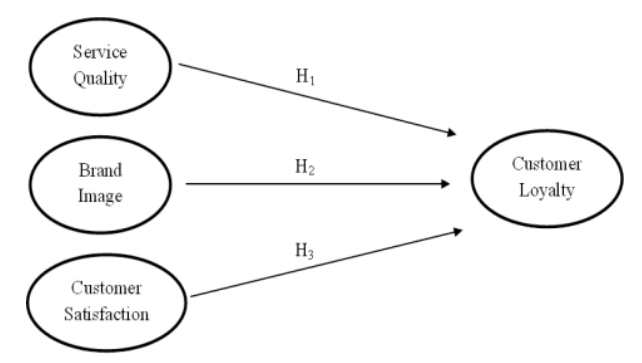

\section{Gambar 1. Model Penelitian}

Sumber : Data diolah, 2020

Berdasarkan model penelitian diatas, dapat dirumuskan model hipotesis penelitian sebagai berikut

H1 : Kualitas pelayanan berpengaruh positif terhadap loyalitas pelanggan pada kafe di Kota Batam.

H2 : Citra merek berpengaruh positif terhadap loyalitas pelanggan pada kafe di Kota Batam.

H3 : Kepuasan pelanggan berpengaruh positif terhadap loyalitas pelanggan pada kafe di Kota Batam.

\section{METODOLOGI PENELITIAN}

\subsection{Rancangan Penelitian}

Penelitian ini menggunakan metode kuantitatif. Metode Kuantitatif adalah metode penelitian yang berasas pada filsafat positivisme, yang digunakan untuk menyelidiki populasi dan sampel tertentu, (Sugiyono, 2018). Penelitian kuantitatif ini berbentuk angka dan analisis menggunakan statistik untuk mengukur serta mendapatkan hasil penelitian melalui kuesioner. Tujuan dilakukannya penelitian ini adalah untuk mengumpulkan data agar dapat mengembangkan ilmu dan mengetahui hubungan antar variabel. 
Karakteristik permasalahan dari penelitian ini adalah mengambil data-data yang dikumpulkan dari beberapa sampel untuk mengetahui bagaimana suatu variabel berpengaruh terhadap variabel lainnya, sehingga menghasilkan signifikan positif.

\subsection{Objek Penelitian}

Objek dalam penyebaran kuesioner penelitian adalah masyarakat yang berdomisili di Kota Batam, masyarakat yang pernah mengunjungi kafe dan memesan makanan penutup di Kota Batam. Kafe yang diteliti adalah kafe yang menjual berbagai makanan penutup selain makanan berat. Penyebaran kuesioner dilakukan dengan melalui digital karena berkembangnya jaman. Berdasarkan teori (Yurdugül, 2008), penelitian ini memiliki minimum responden sebanyak 300 untuk mendapatkan hasil yang lebih baik. Sehingga penelitian ini sudah terkumpul 330 sampel untuk mendapatkan hasil pengujian outliner.

Penyebaran kuesioner melalui penyebaran media sosial, seperti Instagram, Facebook, Whatsapp, dan lainnya. Responden dapat mengisi survei secara individu dengan kuesioner yang telah disediakan pada sistem google form. Kuesioner dibuat dengan bahasa inggris dan Indonesia.

\subsubsection{Metode SAMPLING}

Menurut (Sugiyono, 2003), Sampling adalah sebuah teknik untuk mengambil sampel. Non-Random Sampling Merupakan teknik pengambilan sampel yang tidak memberikan kesempatan kepada semua anggota sampel untuk dijadikan sebagai anggota sampel. Purposive sampling adalah teknik pengambilan sampel dengan menetapkan ciri yang sesuai dengan tujuan.

Metode pengambilan sampel yang dilakukan untuk penelitian adalah menggunakan metode Non-Probability sampling. Berikut ini adalah beberapa kriteria pemilihan sampel yang akan diteliti, yaitu:

1) Responden merupakan pelanggan dari kafe yang ada di Kota Batam.

2) Usia responden dimulai dari 16 tahun hingga di atas 36 tahun.

3) Responden harus berdomisili di Kota Batam.

\section{HASIL PENELITIAN}

\section{DESKRIPSI DEMOGRAFI RESPONDEN}

Pengumpulan data untuk penelitian ini diperoleh dari penyebaran kuesioner bagi pelanggan yang mengunjungi kafe di Kota Batam. Jumlah pengisian kuesioner yang telah disebarkan adalah 360 responden, yang tidak kembali adalah 25 responden dan yang tidak layak diolah adalah 5 responden, sehingga total 330 responden digunakan untuk penelitian ini.

Tabel 4.2 Hasil Jenis Kelamin Responden

\begin{tabular}{lcc}
\hline Responden & Frekwensi & Persentase \\
\hline Laki-laki & 117 & $35.5 \%$ \\
Perempuan & 213 & $64.5 \%$ \\
\hline Total & 330 & $100 \%$ \\
\hline
\end{tabular}

Berdasarkan dari usia, 76 responden berusia 16-20 tahun sebesar 23\%, 203 responden berusia 21-25 tahun sebesar $61.5 \%, 34$ responden berusia 26-30 tahun sebesar 10.3\%, 12 
responden berusia 31-35 tahun sebesar 3.6\%, dan 5 responden berusia 36 tahun ke atas sebesar $1.5 \%$. Terlampir pada Tabel 4.3 .

Tabel 4.3 Frekuensi Usia Responden

\begin{tabular}{lcc}
\hline Responden & Frekwensi & Persentase \\
\hline $16-20$ tahun & 76 & $23.0 \%$ \\
$21-25$ tahun & 203 & $61.5 \%$ \\
$26-30$ tahun & 34 & $10.3 \%$ \\
$31-35$ tahun & 12 & $3.6 \%$ \\
$>36$ tahun & 5 & $1.5 \%$ \\
\hline Total & 330 & $100 \%$ \\
\hline
\end{tabular}

Sumber: Data Primer diolah (2020).

Berdasarkan jenis pekerjaan responden, menunjukkan bahwa mayoritas merupakan mahasiswa sebanyak 172 responden sebesar 52.1\%, pegawai swasta sebanyak 99 responden sebesar 30\%, ibu rumah tangga sebanyak 14 responden sebesar $4.2 \%$, dan wirausaha sebanyak 45 responden sebesar $13.6 \%$. Terlampir pada Tabel 4.4.

Tabel 4.4 Frekuensi Pekerjaan Responden

\begin{tabular}{lcc}
\hline Responden & Frekwensi & Persentase \\
\hline Mahasiswa & 172 & $52.1 \%$ \\
Pegawai Swasta & 99 & $30.0 \%$ \\
Ibu Rumah Tangga & 14 & $4.2 \%$ \\
Wirausaha & 45 & $13.6 \%$ \\
\hline Total & 330 & $100 \%$ \\
\hline
\end{tabular}

Sumber: Data Primer diolah (2020).

Berdasarkan biaya yang dikeluarkan untuk ke kafe Kota Batam, menunjukkan bahwa responden yang mengeluarkan biaya sebesar Rp.0 hingga Rp.200.000 sebanyak 146 responden dengan 44.2\%, kemudian Rp.200.000 hingga Rp.400.000 sebanyak 117 responden dengan 35.5\%, kemudian Rp.400.000 hingga Rp.600.000 sebanyak 32 responden dengan 9.7\%, kemudian Rp.600.000 ke atas sebanyak 35 responden dengan 10.6\%. Terlampir pada Tabel 4.5.

Tabel 4.5 Frekuensi Biaya ke Kafe

\begin{tabular}{lcc}
\hline Responden & Frekwensi & Persentase \\
\hline Rp.0 - Rp.200.000 & 146 & $44.2 \%$ \\
Rp.200.000 - Rp. 400.000 & 117 & $35.5 \%$ \\
Rp.400.000 - Rp.600.000 & 32 & $9.7 \%$ \\
P Rp.600.000 & 35 & $10.6 \%$ \\
\hline Total & 330 & $100 \%$ \\
\hline
\end{tabular}

Sumber: Data Primer diolah (2020).

Berdasarkan jenis kafe di Kota Batam yang sering dikunjungi, sebanyak 49 responden mengunjungi Biscotti Cakery \& Coffee sebesar 14.8\%, kemudian sebanyak 54 responden mengunjungi Meilleur Café \& Patisserie sebesar 16.4\%, kemudian sebanyak 25 
responden mengunjungi Caffein Coffee \& Cake sebesar 7.6\%, kemudian sebanyak 74 responden mengunjungi Lee's Café \& Bar sebesar 22.4\%, kemudian sebanyak 26 responden mengunjungi Tatido Coffee \& Roasters sebesar 7.9\%, kemudian sebanyak 4 responden mengunjungi Pinkupansa Cakery sebesar1.2\%, kemudian sebanyak 22 responden mengunjungi Piccola Stella sebesar 6.7\%, kemudian sebanyak 37 responden mengunjungi Chemistree sebesar 11.2\%, kemudian sebanyak 27 responden mengunjungi Anchor Café \& Roastery sebesar 8.2\%, dan sebanyak 12 responden yang mengunjungi Simetri Coffee sebesar 3.6\%. Terlampir pada Tabel 4.6.

Tabel 4.6 Frekuensi Kafe di Kota Batam

\begin{tabular}{lcc}
\hline Responden & Frekwensi & Persentase \\
\hline Biscotti Cakery \& Coffee & 49 & $14.8 \%$ \\
Meilleur Café \& Patisserie & 54 & $16.4 \%$ \\
Caffein Coffee \& Cake & 25 & $7.6 \%$ \\
Lee's Café \& Bar & 74 & $22.4 \%$ \\
Tatido Coffee Roasters & 26 & $7.9 \%$ \\
Pinkupansa Cakery & 4 & $1.2 \%$ \\
Piccola Stella & 22 & $6.7 \%$ \\
Chemistree & 37 & $11.2 \%$ \\
Anchor Café \& Roastery & 27 & $8.2 \%$ \\
Simetri Coffee & 12 & $3.6 \%$ \\
\hline Total & 330 & $100 \%$ \\
\hline
\end{tabular}

Sumber: Data Primer diolah (2020).

Berdasarkan frekuensi seberapa sering responden mengunjungi kafe di Kota Batam, terdapat 262 responden (79.4\%) mengunjungi kafe sebanyak 1-3 kali dalam sebulan, 37 responden $(11.2 \%)$ mengunjungi kafe sebanyak 4-5kali dalam sebulan, dan 31 responden (9.4\%) mengunjungi kafe lebih dari 6 kali dalam sebulan. Terlampir pada Tabel 4.7.

Tabel 4.7 Frekuensi ke Kafe di Kota Batam

\begin{tabular}{lcc}
\hline Responden & Frekwensi & Persentase \\
\hline $1-3$ kali & 262 & $79.4 \%$ \\
$4-5$ kali & 37 & $11.2 \%$ \\
$>6$ kali & 31 & $9.4 \%$ \\
\hline Total & 330 & $100 \%$ \\
\hline
\end{tabular}

Sumber: Data Primer diolah (2020)

\section{HASIL UJI STATISTIK DESKRIPTIF}

Tabel 4.8 Karakteristik Variabel Loyalitas Pelanggan 


\begin{tabular}{|l|r|r|r|r|}
\hline \multicolumn{1}{|c|}{ Variabel } & \multicolumn{1}{|c|}{ Min } & \multicolumn{1}{c|}{ Max } & \multicolumn{1}{c|}{ Mean } & \multicolumn{1}{c|}{$\begin{array}{c}\text { Std. } \\
\text { Deviasi }\end{array}$} \\
\hline \multicolumn{1}{|c|}{ Loyalitas Pelanggan } & & & $\mathbf{4 . 2 1 1 5}$ & \\
\hline $\begin{array}{l}\text { Saya punya niat untuk tetap memilih kafe } \\
\text { ini. }\end{array}$ & 1.00 & 5.00 & 4.1909 & 0.85227 \\
\hline $\begin{array}{l}\text { Saya memutuskan memilih kafe ini } \\
\text { sebagai pilihan utama. }\end{array}$ & 1.00 & 5.00 & 4.0061 & 0.93884 \\
\hline $\begin{array}{l}\text { Saya merasa lebih baik, ketika saya pergi } \\
\text { ke kafe ini untuk memesan makanan } \\
\text { penutup. }\end{array}$ & 1.00 & 5.00 & 4.1364 & 0.91735 \\
\hline $\begin{array}{l}\text { Saya akan merekomendasikan kafe ini } \\
\text { kepada teman saya. }\end{array}$ & 1.00 & 5.00 & 4.3303 & 0.72932 \\
\hline $\begin{array}{l}\text { Saya akan mengatakan hal positif tentang } \\
\text { kafe ini kepada orang lain. }\end{array}$ & 1.00 & 5.00 & 4.3939 & 0.68147 \\
\hline
\end{tabular}

Sumber: Data primer yang Diolah (2020).

Pada variabel loyalitas pelanggan, perhitungan rata-rata keseluruhan variabel sebesar 42,115 dengan nilai rata-rata tertinggi pada pertanyaan 21 sebesar 43,939, dimana responden akan menceritakan hal positif tentang kafe tersebut pada orang lain. Namun pada pertanyaan 18 , responden masih tidak yakin dengan keputusannya untuk memilih kafe tersebut sebagai pilihan utamanya.

\section{Hasil Uji Hipotesis}

\section{Hasil Uji Signifikansi Simultan (F test)}

Uji signifikansi simultan bertujuan untuk memahami pengaruh variabel independen secara simultan. Dilihat dari tabel 18.

Tabel 4.9

Hasil Uji F (Signifikansi Simultan)

ANOVA

\begin{tabular}{|c|c|c|c|c|c|c|}
\hline \multicolumn{2}{|c|}{ Model } & Sum of Squares & $\mathrm{DF}$ & Mean Square & $F$ & Sig. \\
\hline & Regression & 2025.879 & 3 & 675.293 & 186.336 & $.000^{\mathrm{b}}$ \\
\hline 1 & Residual & 1166.946 & 322 & 3.624 & & \\
\hline & Total & 3192.825 & 325 & & & \\
\hline
\end{tabular}

Hasil uji ini memiliki rumusan hipotesis pada penelitian, yaitu:

$\mathrm{H}_{1}$ : Kualitas Pelayanan secara signifikan berpengaruh positif terhadap loyalitas pelanggan pada kafe di Kota Batam.

$\mathrm{H}_{2}$ : Citra Merek secara signifikan berpengaruh positif terhadap loyalitas pelanggan pada kafe di Kota Batam.

$\mathrm{H}_{3}$ : Kepuasan Pelanggan secara signifikan berpengaruh positif terhadap loyalitas pelanggan pada kafe di Kota Batam.

Pada pengujian ini, bila nilai signifikansi lebih dari 0.05 maka variabel independen secara simultan berpengaruh signifikan terhadap variabel dependen. Tabel di atas menunjukkan nilai Sig 0.000 yang artinya variabel independen secara simultan berpengaruh pada variabel dependen.

\section{Uji Koefisien Determinasi ( $R$ Square)}


Pengujian $R$ Square bertujuan melihat seberapa besar variabel bersifat dependen yang dijelaskan oleh variabel bersifat independen. Dapat dilihat pada Tabel 19.

Tabel 4.10

\section{Hasil Uji Koefisien Determinasi}

\begin{tabular}{c|c|c|c|c}
\multicolumn{5}{c}{ Model Summary $^{\mathbf{b}}$} \\
Model & R & R Square & Adjusted R Square & Std. Error of The Estimate \\
\hline 1 & $0.797^{\mathrm{a}}$ & 0.635 & 0.631 & 1.90370 \\
\hline \multicolumn{5}{c}{ Sumber: Data Primer diolah (2020). }
\end{tabular}

Dapat dilihat bahwa ketiga variabel independen (kualitas pelayanan, citra merek, kepuasan pelanggan) menjelaskan variabel dependen (loyalitas pelanggan) sebesar $63 \%$. Sisanya $37 \%$ didefinisikan oleh faktor lainnya yang tidak ada dalam penelitian ini.

\section{Uji Signifikansi Parameter Individual (t test)}

Uji T diuji untuk menampilkan seberapa besar pengaruh variabel independen secara individual dalam mendeskripsikan variabel dependen. Hasil terlampir pada tabel 20.

Tabel 4.16

\section{Hasil Uji Signifikansi Parameter Individual}

\begin{tabular}{lcccc}
\hline \multicolumn{6}{c}{ Coefficients $^{\mathbf{a}}$} \\
Variabel Independen & Variabel Dependen & $\begin{array}{c}\text { Beta (Coeffi } \\
\text { cients) }\end{array}$ & Sig. & Hipotesis \\
\hline Kualitas Pelayanan & Loyalitas Pelanggan & 0.170 & 0.001 & Signifikan \\
Citra Merek & Loyalitas Pelanggan & 0.174 & 0.000 & Signifikan \\
Kepuasan Pelanggan & Loyalitas Pelanggan & 0.543 & 0.000 & Signifikan \\
\hline
\end{tabular}

Sumber: Data Primer diolah (2020).

Suatu hubungan dinyatakan signifikan apabila nilai Sig lebih kecil dari 0.05. Dari tampilan tabel di atas, variabel kualitas pelayanan berpengaruh secara signifikan terhadap loyalitas pelanggan dikarenakan hasil nilai Sig adalah 0.001. Sedangkan, Beta menunjukkan kualitas pelayanan berpengaruh positif karena nilainya sebesar 0.170.

Selanjutnya ada hasil uji T untuk variabel citra merek. Hasilnya menunjukkan citra merek secara signifikan berpengaruh positif pada loyalitas pelanggan. Karena nilai Sig sebesar 0.000 dan nilai Beta 0.174.

Dan yang terakhir, hasil uji T dilakukan pada variabel kepuasan pelanggan menunjukkan nilai Sig sebesar 0.000 dan nilai Beta 0.543. Dengan ini, dapat dinyatakan bahwa kepuasan pelanggan secara signifikan berpengaruh positif pada loyalitas pelanggan.

Kesimpulannya, dari total 3 (tiga) hipotesis yang dirumuskan pada penelitian ini, yaitu $\mathrm{H}_{1}, \mathrm{H}_{2}$, dan $\mathrm{H}_{3}$ dapat diterima karena semuanya telah signifikan dan berpengaruh secara positif. Dapat disimpulkan semakin tinggi nilai Beta maka semakin besar pengaruhnya pada loyalitas pelanggan. 


\section{KESIMPULAN}

Hasil analisia penelitian ini menggunakan program SPSS (Statistical Package for the Social Sciences) versi 21 untuk windows. Untuk menganalisa data, maka harus mengumpul data dan dilakukan dengan menyebarkan kuesioner melalui media sosial yakni line, instagram, facebook, dan lainnya. Setelah menganalisis penelitian ini, hasil yang didapatkan adalah:

a. Dalam menguji H1 kualitas pelayanan diterima, dikarenakan variabel tersebut bersignifikan positif terhadap loyalitas pelanggan. Sehingga hasil yang di analisis termasuk sesuai dengan penelitian (Sukerta et al., 2020).

b. Dalam menguji H2 citra merek diterima, dikarenakan variabel tersebut bersignifikan positif terhadap loyalitas pelanggan. Sehingga hasil yang di analisis termasuk sesuai dengan penelitian (Azizan \& Yusr, 2019).

c. Dalam menguji H3 kepuasan pelanggan diterima, dikarenakan variabel tersebut bersignifikan positif terhadap loyalitas pelanggan. Sehingga hasil yang di analisis termasuk sesuai dengan penelitian (Hafez \& Akther, 2017).

\section{2, KETERBATASAN}

Menurut pengalaman langsung dalam melakukan penelitian, adapun beberapa keterbatasan yaitu:

a. Pada proses pengisian kuesioner, adakala dimana data yang diisi oleh responden tidak sama dikarenakan perbedaan kafe yang dikunjungi dan pengalaman kafe yang dialami oleh tiap responden berbeda-beda.

b. Kafe yang diteliti di Kota Batam adalah satu-satunya, karena tidak memiliki cabang lain sehingga kuesioner yang diisi hanyalah pelanggan yang berdomisili di Batam.

\section{REKOMENDASI}

Dari hasil peneliltian di atas, peneliti memiliki memberikan beberapa rekomendasi yang bisa dijadikan evaluasi tambahan untuk kedepannya, yaitu:

a. Untuk universitas diharapkan dapat menyediakan library online yang lebih mudah dimengerti cara kerjanya, agar mahasiswa dapat dengan mudah memperoleh apa yang diinginkan.

b. Untuk peneliti selanjutnya yang hendak melakukan penelitian sejenis, agar dapat melibatkan lebih banyak variabel lainnya seperti kepercayaan pelanggan (customer trust) sehingga bisa mendapatkan hasil yang lebih maksimal.

c. Peneliti selanjutnya direkomendasikan agar dapat meneliti objek penelitian lainnya yang khusus menjual makanan penutup untuk lebih membuktikan teori ini, seperti Taka Deli, Yan Yan Cake House, Tremondi Cake, Smith Patisserie, dan lainnpassages, and more recently with desktop publishing software like Aldus PageMaker including versions of Lorem Ipsum.

\section{UCAPAN TERIMA KASIH}

Terima kasih kepada Universitas Internasional Batam (UIB), Rekan mahasiswa, dan keluarga. Karya ilmiah ini saya persembahkan untuk seluruh pembaca khususnya yang bergerak pada bidang Pariwisata. Harapan saya akan banyak karya ilmiah yang lahir untuk meningkatkan kualitas penyedia jasa Pariwisata yang dapat memperkuat Ekonomi Pariwisata 


\section{DAFTAR PUSTAKA}

Agyapong, G. K. . (2011). The Effect of Service Quality on Customer Satisfaction in the Utility Industry - A Case of Vodafone (Ghana). International Journal of Business and Management, 6(5), 203-210. https://doi.org/10.5539/ijbm.v6n5p203

Albayrak, T., Karasakal, S., Kocabulut, Ö., \& Dursun, A. (2019). Customer Loyalty Towards Travel Agency Websites: The Role of Trust and Hedonic Value. Journal of Quality Assurance in Hospitality and Tourism, O(0), 1-28. https://doi.org/10.1080/1528008X.2019.1619497

Ali, F., Zhou, Y., Hussain, K., Nair Kumar, P., \& Ragavan, N. A. (2016). 2016_Ali F et al_Does Higher Education SQ Effect SS Image and Loyalty A Study of IS in Malaysian PU. Quality Assurance in Education, 24(1).

Anh, T. T., Duc, T. T., Thi, T. T., \& Hong, N. T. (2020). Evaluating the determinants of Vietnamese frequent flyers' loyalty in civil aviation industry: The case of Delta air lines. Management Science Letters, 10(2), 391-398. https://doi.org/10.5267/j.msl.2019.8.031

Azizan, N. S., \& Yusr, M. M. (2019). the Influence of Customer Satisfaction, Brand Trust, and Brand Image Towards Customer Loyalty. International Journal of Entrepreneurship and Management Practices, 2(7), 93-108. https://doi.org/10.35631/ijemp.270010

Baek, W. Y., Kim, K., Kim, D. H., \& Byon, K. K. (2020). The impacts of the perceived golf course brand globalness on customer loyalty through multidimensional $\begin{array}{llll}\text { perceived values. } & \text { Sustainability } & \text { (Switzerland), } & 12 .\end{array}$ https://doi.org/10.3390/su12030978

Chidi, O. F., Tochukwu, T., \& Esther, C. (2020). Product Differentiation and Customer Brand Loyalty in Selected Soap / Detergent Firms in Anambra State. VII(11), 53905405.

Chiou, M. R., Chao, S. L., \& Hsieh, H. Y. (2020). The Moderating Role of Service Recovery on Customer Loyalty in the Context of Cruise Passengers. Maritime Policy and Management, 1-17. https://doi.org/10.1080/03088839.2020.1742396

Cronin, J. J., \& Taylor, S. A. (1992). Measuring Service Quality: A Reexamination and Extension. Journal of Marketing, 56, 405-420. https://doi.org/10.2307/1252296

Czepiel, J. A. (1990). Service encounters and service relationships: Implications for research. Journal of Business Research, 20(1), 13-21. https://doi.org/10.1016/01482963(90)90038-F

Danibrata, A. (2019). 2019 Enhancing Customer Loyalty Through Product Quality, Brand. 20(2), 27-31.

Demirci Orel, F., \& Kara, A. (2014). Supermarket self-checkout service quality, customer satisfaction, and loyalty: Empirical evidence from an emerging market. Journal of Retailing and Consumer Services. https://doi.org/10.1016/j.jretconser.2013.07.002

Dölarslan, E. S. (2014). Assessing the effects of satisfaction and value on customer loyalty behaviors in service environments: High-speed railway in Turkey as a case study. Management Research Review, 37(8), 706-727. https://doi.org/10.1108/MRR-06-2013-0152

Durmaz, Y., Cavusoglu, S., \& Ozer, O. (2018). The Effect of Brand Image and Brand Benefit on Customer Loyalty: The Case of Turkey. International Journal of Academic Research in Business and Social Sciences, 8(5), 528-540. https://doi.org/10.6007/ijarbss/v8-i5/4140 
Fauzi, A. A. (2018). ELECTRONIC SERVICE QUALITY ON MOBILE APPLICATION OF ONLINE TRANSPORTATION SERVICES. Jurnal Manajemen Indonesia, 18(1), 13-27. https://doi.org/10.25124/jmi.v18i1.1256

Ferdiawan, Y, Hermawan, A., Wardana, L. W., Arief, M., \& . S. (2018). Satisfaction as Effect Mediation of Brand Image and Customer Relationship Management on Customer's Loyalty. KnE Social Sciences, 3(3), 34. https://doi.org/10.18502/kss.v3i3.1872

Ferdiawan, Yusva, Hermawan, A., Wardana, L. W., Arief, M., \& Sarbini. (2018). Satisfaction as Effect Mediation of Brand Image and Customer Relationship Management on Customer's Loyalty. KnE Social Sciences, 3(3), 34-50. https://doi.org/10.18502/kss.v3i3.1872

Ferdinand, A. (2011). Metode Penelitian Manajemen Pedoman Penelitian untuk Penulisan Skripsi Tesis dan disertai Ilmu Manajemen. In Semarang: Universitas Diponegoro.

Fotaki, M. (2015). Why and how is compassion necessary to provide good quality healthcare? In International Journal of Health Policy and Management. https://doi.org/10.15171/ijhpm.2015.66

Ghozali, I. (2011). Aplikasi Analisis Multivariate Dengan Program IBM SPSS 19 (edisi kelima). In Aplikasi Analisis Multivariate dengan program SPSS.

Ghozali, I. (2016). Ghozali, Imam. 2016. Aplikasi Analisis Multivariate dengan Program SPSS. Semarang: Badan Penerbit UNDIP. In Analisis Multivariate dengan Program SPSS (p. 103).

Ghozali, I. (2018). Aplikasi Analisis Multivariate dengan Program IBM SPSS 25 (ke-9th ed.). Semarang: Badan Penerbit Universitas Diponegoro. (Edisi 9). Semarang: Badan Penerbit Universitas Diponegoro.

Gogoi, B. J. (2020). Service quality measures: How it impacts customer satisfaction and loyalty. International Journal of Management, 11(3), 354-365. https://doi.org/10.34218/IJM.11.3.2020.038

Gujarati, D. N. (2004). Basic econometrics. The Mc-Graw Hill. In New York.

Hafez, M., \& Akther, N. (2017). Determinants of Customer Loyalty in Mobile Telecommunication Industry in Bangladesh. Global Journal of Management and Business Research: A and Management, 17(1), 141-148.

Hair, J. F., Black, W. C., Babin, B. J., \& Anderson, R. E. (2011). Multivariate Data Analysis. In Vectors (p. 92). https://doi.org/10.1016/j.ijpharm.2011.02.019

Hair, J. F., Black, W. C., Babin, B. J., \& Anderson, R. E. (2017). Multivariate Data Analysis: Seventh Edition. In Prentice Hall.

Hapsari, R., Clemes, M. D., \& Dean, D. (2017). The impact of service quality, customer engagement and selected marketing constructs on airline passenger loyalty. International Journal of Quality and Service Sciences, 9(1), 21-40. https://doi.org/10.1108/IJQSS-07-2016-0048

Hapsari, R., Hussein, A. S., \& Handrito, R. P. (2020). Being Fair to Customers: A Strategy in Enhancing Customer Engagement and Loyalty in the Indonesia Mobile Telecommunication Industry. Services Marketing Quarterly, 41(1), 49-67. https://doi.org/10.1080/15332969.2019.1707375

Irshad, A., Rahim, A., Khan, M. F., \& Khan, M. M. (2017a). THE IMPACT OF CORPORATE SOCIAL RESPONSIBILITY ON CUSTOMER SATISFACTION AND CUSTOMER LOYALTY, MODERATING EFFECT OF CORPORATE IMAGE (EVIDENCE FROM PAKISTAN) As the businesses are growing very fast 
today, there are different techniques and tools to make. City University Research Journal, 63-73.

Irshad, A., Rahim, A., Khan, M. F., \& Khan, M. M. (2017b). THE IMPACT OF CORPORATE SOCIAL RESPONSIBILITY ON CUSTOMER SATISFACTION AND CUSTOMER LOYALTY, MODERATING EFFECT OF CORPORATE IMAGE (EVIDENCE FROM PAKISTAN) As the businesses are growing very fast today, there are different techniques and tools to make. City University Research Journal, AIC, 63-73.

Ismail, A., \& Yunan, Y. S. M. (2016). SERVICE QUALITY AS A PREDICTOR OF CUSTOMER SATISFACTION AND CUSTOMER LOYALTY. Scientific Journal of Logistic, 12(4), 269-283. https://doi.org/10.17270/J.LOG.2016.4.7

Jung, J., Kim, S. J., \& Kim, K. H. (2020). Sustainable marketing activities of traditional fashion market and brand loyalty. Journal of Business Research, 120(August 2019), 294-301. https://doi.org/10.1016/j.jbusres.2020.04.019

Khokhar, Z., \& Khokhar, R. (2020). Influential Factors on Customer Loyalty of La Moosh (Café), Hyderabad, Pakistan: An Empirical Approach. Journal of Economics, Management and Trade, 26(2), 15-25. https://doi.org/10.9734/jemt/2020/v26i230224

Kim, M. R., Vogt, C. A., \& Knutson, B. J. (2015). Relationships Among Customer Satisfaction, Delight, and Loyalty in the Hospitality Industry. Journal of Hospitality and Tourism Research. https://doi.org/10.1177/1096348012471376

Kusumah, E. P. (2018). CUSTOMER LOYALTY MODEL: CUSTOMER SATISFACTION AS INTERVENING VARIABLE. ECOFORUM, 7(2), 15. papers2://publication/uuid/512EBCE8-D635-4348-A67D-22DD52988F4C

Lahap, J., Ramli, N. S., Said, N. M., Radzi, S. M., \& Zain, R. A. (2016). A Study of Brand Image towards Customer's Satisfaction in the Malaysian Hotel Industry. Procedia Social and Behavioral Sciences, 149-157. https://doi.org/10.1016/j.sbspro.2016.05.430

Makanyeza, C., \& Chikazhe, L. (2017). Mediators of the relationship between service quality and customer loyalty: Evidence from the banking sector in Zimbabwe. International Journal of Bank Marketing, 35(3), 540-556. https://doi.org/10.1108/IJBM-11-2016-0164

Meyer, N., \& Meyer, D. F. (2016). THE RELATIONSHIP BETWEEN THE CREATION OF AN ENABLING ENVIRONMENT AND ECONOMIC DEVELOPMENT: A COMPARATIVE ANALYSIS OF MANAGEMENT AT LOCAL GOVERNMENT SPHERE. Polish Journal of Management Studies, 14(2), 150160. https://doi.org/10.17512/pjms.2016.14.2.14

Minar, D., \& Safitri, A. (2017a). Brand Image and Product Quality on Customer Loyalty (Survey in Cekeran Midun). Trikonomika, 16(1), 43. https://doi.org/10.23969/trikonomika.v16i1.420

Minar, D., \& Safitri, A. (2017b). Brand Image and Product Quality on Customer Loyalty (Survey in Cekeran Midun). Trikonomika, 16(1), 43-50. https://doi.org/10.23969/trikonomika.v16i1.420

Mustafa, Z. (2009). Mengurai Variabel hingga Instrumentasi. Graha Ilmu.

Nasrul, Said, L. R., \& Faidah, A. N. (2020). Improving customer loyalty for automotive industry of Indonesia through brand prominence, self-connection and authenticity: Mediating role of online trust. International Journal of Innovation, Creativity and Change, 11(6), 191-209. 
Njelita, C. I., \& Anyasor, O. M. (2020). Customer Loyalty and Patronage of Quick Service Restaurant in Nigeria. British Journal of Marketing Studies, 8(2), 54-76. https://doi.org/10.37745/bjms/vol8.no2.pp54-76.2020

Njelita, C., \& Marcus, A. (2020). Customer Loyalty and Patronage of Quick Service Restaurant in Nigeria. British Journal of Marketing Studies, 8(2), 54-76. https://doi.org/10.37745/bjms/vol8.no2.pp54-76.2020

Oliver, R. L. (2010). Consumer Brand Loyalty. In Wiley International Encyclopedia of Marketing. https://doi.org/10.1002/9781444316568.wiem03025

Perdana Kusumah, E. (2018). CUSTOMER LOYALTY MODEL: CUSTOMER SATISFACTION AS INTERVENING VARIABLE. ECOFORUM, 7(April), Issue 2(15).

Reichheld, F. F., \& Sasser, W. E. (1990). Zero defections: quality comes to services. Harvard Business Review, 68(5), 105-111.

Rua, S., Saldanha, E. D. S., \& Amaral, A. M. (2020). Examining the Relationships among Product Quality, Customer Satisfaction and Loyalty in the Bamboo Institute, Dili, Timor-Leste. Timor Leste Journal of Business and Management, 2(1), 33-44. https://doi.org/10.51703/bm.v2i2.28

Saleem, H., \& Raja, N. S. (2014). The impact of service quality on customer satisfaction, customer loyalty and brand image: Evidence from hotel industry of Pakistan. Middle - East Journal of Scientific Research, 19(5), 706-711. https://doi.org/10.5829/idosi.mejsr.2014.19.5.21018

Santoso, S. (2007). Structural Equation Modelling Konsep dan Aplikasi dengan program AMOS. In Structural Equation Modelling Konsep dan Aplikasi dengan program AMOS.

Shamsudin, M. F., Esa, S. A., \& Ali, A. M. (2019). Determinants of customer loyalty towards the hotel industry in Malaysia. International Journal of Innovation, Creativity and Change, 6(9), 21-29.

Sugiyono. (2003). Metode Penelitian Bisnis. Pusat Bahasa Depdiknas.

Sugiyono, D. (2018). Metode penelitian kuatintatif, kualitatif dan R \& D / Sugiyono. In Bandung: Alfabeta.

Sukerta, M., Putu Agung, A. A., \& Sujana, I. W. (2020). Effect of Service Quality and Corporate image on Customer Loyalty with Customer Satisfaction as Mediation Variables (Study at PT. BPR. Padma, Denpasar-Bali). International Journal of Contemporary Research and Review, 11(01), 21729-21740. https://doi.org/10.15520/ijcrr.v11i01.783

Sürücü, Ö., Öztürk, Y., Okumus, F., \& Bilgihan, A. (2019). Brand awareness, image, physical quality and employee behavior as building blocks of customer-based brand equity: Consequences in the hotel context. Journal of Hospitality and Tourism Management, $\quad 40$ (November 2018), 114-124. https://doi.org/10.1016/j.jhtm.2019.07.002

Tantri Yanuar R. Syah, I. (2019a). The effect of service quality and customer satisfaction on customer loyalty. International Journal of Bank Marketing, 38(2), 384-405. https://doi.org/10.1108/ijbm-03-2019-0096

Tantri Yanuar R. Syah, I. (2019b). The effect of service quality and customer satisfaction on customer loyalty. Journal of Multidisciplinary Academic, 3(5), 146-150. https://doi.org/10.1108/ijbm-03-2019-0096

Tjiptono, F. (2006). Manajemen Jasa Edisi Pertama. In Manajemen Jasa.

Tucker, W. T., \& Levy, S. J. (1979). Marketplace Behavior. Its Meaning for Management. 
Journal of Marketing, 43(3), 126. https://doi.org/10.2307/1250156

Wantara, P., \& Tambrin, M. (2019). ITHJ International Tourism and Hospitality Journal The Effect of Price and Product Quality Towards Customer Satisfaction and Customer Loyalty on Madura Batik. International Tourism and Hospitality Journal, 2(1), 1-9.

WIJAYA, T. (2011). Manajemen Kualitas Jasa. PT Indeks Kembangan, Jakarta. Jurnal EMBA: Jurnal Riset Ekonomi, Manajemen, Bisnis Dan Akuntansi.

Wilson, N. (2018). The Impact of Service Quality and Brand Image toward Customer Loyalty in the Indonesian Airlines Industry. Jurnal Manajemen Indonesia, 18(3), 222-234. https://doi.org/10.25124/jmi.v18i3.1734

Yang, K. F., Yang, H. W., Chen, Y. Y., \& Fan, C. C. (2019). Research on the service quality, customer satisfaction, customer loyalty in the cosmetics industry - Taking LANEIGE as an example. ACM International Conference Proceeding Series, 3237. https://doi.org/10.1145/3355966.3355990

Ying Lee, C. (2019). Does Corporate Social Responsibility Influence Customer Loyalty in the Taiwan Insurance Sector? The role of Corporate Image and Customer Satisfaction. Journal of Promotion Management, 25(1), 43-64. https://doi.org/10.1080/10496491.2018.1427651

Yurdugül, H. (2008). Minimum sample size cronbach's coefficient alpha: A Monte-Carlo study. Hacettepe Egitim Dergisi, 35, 397-405. 